\title{
Género, sociabilidades y tensiones barriales: el riesgo del desalojo. Buenos Aires, 1780-1820
}

Gender, Sociabilities and Neighbourhood Tensions: The risk of Eviction. Buenos Aires, $1780-1820$

Genre, sociabilité et tensions du voisinage: le risque d'expulsion. Buenos Aires, 1780-1820

\section{María Alejandra Fernández}

\section{OpenEdition}

\section{Journals}

Edición electrónica

URL: http://journals.openedition.org/rhj/4167

DOI: $10.4000 /$ rhj. 4167

ISSN: 0719-4153

Editor

ACTO Editores Ltda

Referencia electrónica

María Alejandra Fernández, « Género, sociabilidades y tensiones barriales: el riesgo del desalojo. Buenos Aires, 1780-1820 », Revista Historia y Justicia [En línea], 11 | 2018, Publicado el 18 octubre 2018, consultado el 27 julio 2020. URL : http://journals.openedition.org/rhj/4167 ; DOI : https:// doi.org/10.4000/rhj. 4167

Este documento fue generado automáticamente el 27 julio 2020.

Revista Historia y Justicia 


\section{Género, sociabilidades y tensiones barriales: el riesgo del desalojo. Buenos Aires, 1780-1820}

Gender, Sociabilities and Neighbourhood Tensions: The risk of Eviction. Buenos

Aires, 1780-1820

Genre, sociabilité et tensions du voisinage: le risque d'expulsion. Buenos Aires, $1780-1820$

María Alejandra Fernández

\section{NOTA DEL EDITOR}

Recibido: 08 de julio de 2018 / Aceptado: 30 de septiembre de 2018

\section{Introducción}

Este artículo indaga en dos expedientes judiciales incoados en la ciudad de Buenos Aires a principios del siglo XIX, con el objeto de analizar la relación entre justicias, injurias y desalojos. La historia sociocultural ha estudiado en profundidad a las injurias -desde los trabajos pioneros de la década de 1980 - como un mirador privilegiado para acceder a los diferentes sentidos del honor, debido a que expresan -de manera condensada e invertida- los distintos pilares en los que se basaba la respetabilidad social ${ }^{1}$. En este sentido, se ha señalado que el lenguaje específico ${ }^{2}$ de los insultos presenta una definición a la inversa de aquellos aspectos que -en un determinado contexto histórico y socio-demográfico- se consideraban centrales para estimar a hombres y mujeres como personas honorables y dignas de respeto. De este modo, estos pleitos han sido considerados como una fuente valiosa para acceder a las complejas jerarquías sociales, étnicas y de género. Paralelamente, los gestos agraviantes y las injurias han sido 
analizados en el marco de las lógicas de la sociabilidad, la conflictividad y la violencia popular urbana, aportando de manera significativa a la reconstrucción de los mecanismos formales e informales de clasificación, de jerarquización, de degradación y de sanción social ${ }^{3}$.

2 En las últimas dos décadas se ha asistido a una multiplicación de estudios sobre esta temática, analizándose con mayor amplitud el carácter ampliamente extendido, polisémico, disputado y negociable del honor; se ha profundizado en el estudio de las "voces" y los actos insultantes; se ha recuperado la historicidad de los agravios verbales en el mediano y largo plazo, rastreando rupturas, continuidades, procesos de resignificación y especificidades regionales ${ }^{4}$. La primera aproximación a la problemática de los insultos -que se focalizaba esencialmente en el sentido de las palabras- ha sido enriquecida al incorporar el lenguaje gestual y físico que formaba parte integral del vocabulario de la ofensa, estableciendo interesantes conexiones con las partes del cuerpo involucradas y con los rituales de deferencia y de castigo ${ }^{5}$. Más recientemente, el análisis de las sociabilidades barriales ha mostrado las potencialidades de entender el lenguaje corporal como portador de una gramática y una sintaxis específica que acompañaba la evaluación social de los "otros". . Por otro lado, desde la historia de las sensibilidades se han estudiado estos conflictos interpersonales como una ventana de acceso a las emociones, los afectos y las pasiones. Las causas por injurias han sido recorridas de una manera novedosa, al ser percibidas como valiosos registros de subjetividades y reservorios desde donde acceder a las sensibilidades de los sujetos, vinculadas a los anhelos, los temores, los celos, los desconsuelos, la envidia, la venganza, la ira, la rabia y la vergüenza ${ }^{7}$.

Dentro de las aproximaciones recientes, las indagaciones que exploran los usos de la justicia y de la violencia, y las estrategias desplegadas por los justiciables frente a los tribunales, reconocen un estímulo insoslayable en la renovada historia social de la justicia y/o en los aportes invaluables de la historia crítica del derecho. A diferencia de la mirada más tradicional, que se había concentrado principalmente en las leyes, los aspectos normativos y las características de las instancias de administración de justicia, se fue afianzando otra perspectiva "en la que adquieren un nuevo protagonismo los actores y las prácticas, los usos de la ley y sus manipulaciones posibles por parte de legos y letrados, profanos y expertos". En este abordaje renovador, los archivos judiciales son considerados portadores de corpus fundamentales para analizar las formas en que se despliegan y dirimen múltiples conflictos, las políticas de control social, las prácticas y estrategias desplegadas por los actores frente a los juzgados y los discursos hegemónicos y contra-hegemónicos que se articulan en los tribunales. De este modo, la arena judicial es percibida como "un mirador privilegiado no sólo para verificar el cumplimiento o violación de las leyes, sino especialmente para registrar la confrontación, apropiación y diseminación de valores, conceptos, prácticas y discursos?.

4 En las investigaciones sobre Hispanoamérica colonial se han realizado valiosas contribuciones en relación con el problema del recurso a la justicia por parte de los sectores subalternos. Si bien las preocupaciones iniciales se desarrollaron alrededor de las llamadas "batallas jurídicas" de los indios litigantes ${ }^{10}$, estudios más recientes se dedicaron a otros grupos sociales e incorporaron la perspectiva de género, ofreciendo variadas aproximaciones a las experiencias de la ley y la justicia a través de las demandas sustanciadas por mujeres, hijos/as, esclavos, peones o arrendatarios en 
defensa de sus derechos ${ }^{11}$. Dentro de los enfoques más novedosos, se encuentran los estudios provenientes originalmente de la Historia crítica del derecho, que han enriquecido significativamente los conocimientos de los historiadores sociales y culturales, al iluminar la profunda alteridad de cultura jurídica (y política) que caracterizaba al período, y que le ha otorgado nuevos sentidos a las investigaciones al renovar las preguntas y las formas de abordaje de los procesos judiciales ${ }^{12}$.

\section{Fuentes, objetivos y perspectiva de análisis}

En diálogo con los desarrollos historiográficos señalados en el apartado anterior, este trabajo intenta ofrecer una aproximación a una problemática menos transitada: la relación entre injurias, justicias y desalojos. El cruce que se propone para la indagación focaliza en una situación de naturaleza doblemente excepcional. En primer lugar, si se recorre el archivo criminal partiendo de los pleitos judiciales por injurias, se evidencia que el desalojo -como resultado del proceso- era una determinación muy poco frecuente. En segundo lugar, tampoco se registran sentencias que operen este cruce, indagando en las causas de los tribunales civiles, donde la figura de la expulsión aparece más vinculada a otro tipo de conflictividad, de naturaleza diferente: la ocupación de tierras, las disputas por montos y pagos del arrendamiento o la afirmación de los derechos de los propietarios, que conducía al desalojo de ocupantes de hecho o inquilinos ${ }^{13}$.

6 Esta excepcionalidad, sin embargo, posibilita ahondar en el fracaso -real o aparente- de un recurso judicial interpuesto en el lenguaje del honor, que permite acceder -por un lado- a las dinámicas de interacción, conflictividad y sociabilidad barrial; a las expresiones explícitas o más sutiles de reconocimiento o de repudio; pero, fundamentalmente, a la distancia entre expectativas y resultados a la hora de acudir a los juzgados; a los costos imprevistos de la judicialización de los conflictos; a la posibilidad de exclusión social -como resultado de las discordias y el escándalo-, materializada en el riesgo de expulsión del barrio; a la cultura jurídico-judicial de las y los litigantes, así como la de los encargados de impartir justicia y, finalmente, a las estrategias diseñadas para enfrentar esa amenaza inesperada. Si bien este artículo se focaliza en el microanálisis de dos expedientes, presupone el conocimiento previo del conjunto mayor de las causas sustanciadas entre 1780 y $1820^{14}$.

7 En relación con la unidad espacial de análisis, el trabajo se centra en un período histórico en el cual la ciudad de Buenos Aires experimentó una serie de cambios trascendentes. Partiendo de una posición secundaria y marginal dentro del Imperio, la urbe fue una pieza clave y estratégica en el proyecto reformista borbónico, hasta que el colapso de la monarquía, la revolución y la guerra condujeron a la crisis final del orden colonial, a la progresiva transformación de las jerarquías estamentales y corporativas impuestas con la dominación hispana y a la redefinición de las bases en las que descansaba la legitimidad para el ejercicio del poder político.

El recorte temporal propuesto se inicia, entonces, con el crecimiento y el dinamismo que las reformas borbónicas le imprimieron a la región rioplatense. Dentro de las político-administrativas, las más relevantes fueron la creación del Virreinato del Río de la Plata en 1776, quedando la ciudad puerto convertida en la nueva capital, la recuperación de Colonia del Sacramento, la presencia reforzada de un aparato militar reorganizado, la instalación del régimen de intendencias y el restablecimiento de la 
Audiencia. En el plano económico, el Reglamento de Libre Comercio de 1778 habilitó al puerto para comerciar con otros dentro de la Península, fomentándose así el comercio ultramarino y la circulación mercantil interregional. En las últimas décadas del siglo XVIII, el crecimiento demográfico de la ciudad obedeció a la llegada de numerosos migrantes de Europa -en especial de la metrópoli-, entre ellos comerciantes, militares y funcionarios al servicio real, pero también arribó un número importante de españoles que nunca se integraron a la élite, sino que se incorporaron a las clases populares urbanas. Este escenario pujante atrajo también a migrantes internos de otras zonas del virreinato y el auge económico demandó el ingreso de un número muy importante de esclavos. Si en 1744 la ciudad contaba con 11.600 habitantes, en 1778 ya tenía 26.125 y en 1810 llegaba a 42.540, de modo tal que el número de habitantes se quintuplicó entre 1744 y 1810, creciendo a un ritmo superior al de Lima o al de Ciudad de México ${ }^{15}$. Esta población, en franco y acelerado crecimiento, demandaba una amplia variedad de productos artesanales y alimentos, mientras que la nueva élite virreinal -más consolidada- requería productos suntuarios y le daba un aire un poco más sofisticado y algo de brillo a la que hasta entonces no era más que una pobre aldea, bastante lejana en términos geográficos y sociales de las grandes capitales del Imperio ${ }^{16}$.

9 Si bien la ciudad constituye el espacio amplio en el que se sitúa esta investigación y, como tal, está sujeta a determinadas instancias que tienen potestades jurisdiccionales, los conflictos específicamente analizados se desarrollan en dos barrios puntuales: el Alto de San Pedro y La Piedad ${ }^{17}$. Estos espacios residenciales, de perfil humilde, eran claramente ajenos a los de la élite de grandes comerciantes y funcionarios de alto rango, que compartían la cúspide de una jerarquía social basada en la ascendencia, la riqueza, la preeminencia y el status.

10 En estos barrios habitaban entremezclados miembros de los sectores medios y un número elevado de pobres. Entre los primeros, se encontraban individuos que eran funcionarios públicos menores o que se dedicaban a las profesiones liberales, comerciantes más modestos, algunos maestros artesanos, religiosos y pequeños propietarios rurales. Dentro de los pobres urbanos, aquellos definidos como integrantes de la "plebe"18 conformaban un grupo sumamente heterogéneo, multiocupacional y multiétnico, que -a su vez- estaba internamente jerarquizado. En este sentido, eran "plebeyos" todos los que compartían una posición subalterna dentro de la sociedad, por su color, ocupación, falta de respetabilidad, pobreza material, situación de dependencia o inestabilidad laboral, movilidad espacial frecuente $y$, en muchos casos, por la imposibilidad de formar un hogar. Si bien la plebe incluía a casi la totalidad de los que no eran considerados blancos (negros, pardos, mulatos), también había blancos pobres en sus filas y, si efectivamente la mayoría se dedicaba a tareas no calificadas, también el grueso de los oficiales y aprendices de las artesanías formaban parte de este grupo. Sin embargo, no todos eran plebeyos, ya que, dentro de las clases populares, había un sector privilegiado integrado por inmigrantes de la Península -que llegaron como polizones, criados de personajes importantes, marineros o soldados-, pero que nunca lograron acceder a la fortuna que les hubiera permitido formar parte de los grupos de poder locales ${ }^{19}$. Estos españoles eran pobres en dos sentidos: tanto en recursos materiales como en recursos relacionales $\mathrm{y}$, en ese aspecto, tenían similares condiciones de vida que las clases bajas. Sin embargo, contaban con algunas ventajas que los diferenciaban, como la pertenencia al grupo de peninsulares y la limpieza de sangre, hallándose -en consecuencia- en el cruce entre dos adscripciones sociales. Si bien formaban parte de los sectores medios y bajos de la población, una serie de 
factores los distinguían del resto de los integrantes de las clases populares: ocupaban lugares diferenciados en la estructura socio-ocupacional, dedicándose a tareas que les permitían mejores ingresos $\mathrm{y}$, desde las cuales, se generaban relaciones de subordinación con otros miembros de los sectores populares. La mayoría de este grupo de peninsulares se dedicaba a actividades comerciales (pulperos) y un porcentaje significativo a oficios artesanales. Este perfil social, tan complejo, fluctuante, como heterogéneo, caracterizaba a los barrios donde se localizaban los conflictos que analizaremos a continuación.

11 Los casos por injurias que hemos seleccionado comparten algunas características: involucran a dos mujeres casadas -por ende, también necesariamente, en forma directa o indirecta, a sus maridos; ambos registran injurias verbales y reales desplegadas en el marco de roces y disputas vecinales; se trata de familias consideradas blancas, que pertenecen a sectores sociales modestos -aunque no en situación de extrema pobreza; las causas evidencian la importancia de tensiones y solidaridades barriales, así como el papel fundamental que cumplen los miembros del vecindario como testigos y también a través de la puesta en circulación no sólo de rumores, sino de información central y decisiva de naturaleza extrajudicial. A diferencia de los procesos que culminaron con un desenlace satisfactorio para el querellante (que implicaba la reparación del honor mancillado a través de la retractación, el perdón, el pago de costas, el desistimiento luego de un acuerdo conciliatorio y/o la reparación económica si hubo daños físicos o materiales), se trata de dos expedientes que -en principio- fracasan al invocar el lenguaje del honor en el marco de una causa por injurias. Otro punto que tienen en común (que no es en absoluto novedoso, ya que era muy frecuente) es el insulto sexual dirigido a las mujeres: "puta". En ambos pleitos, este epíteto se expresa junto con otros términos que se asociaban para orientar o potenciar la significación que, a pesar de ser evidente, presentaba connotaciones variadas. Sin embargo, más allá de los aspectos compartidos, las dos causas judiciales presentan algunas diferencias interesantes que justifican su elección para este análisis y que irán siendo señaladas en las páginas que siguen.

\section{Petrona y Nicolasa: la sombra del desalojo como resultado inesperado de la judicialización del conflicto}

Casi dos semanas después de haber sido injuriada, Doña Petrona Caldevilla (casada con Don Manuel Migolla) se dirigió al Cabildo, dispuesta a incoar una querella contra su vecina Nicolasa Correa (esposa de José Martínez) ${ }^{20}$, por haberla golpeado e insultado públicamente. Es ahí que el Alcalde de 2do voto la anoticiara de que no podía entender en el pleito porque la parte contraria gozaba de fuero militar. En realidad, los dos hombres integraban las milicias, uno en el cuerpo de artillería y otro en el de infantería. El fuero situaba a los milicianos fuera del alcance de la justicia ordinaria, quedando bajo la órbita de la jurisdicción militar, no solo los soldados, sino también sus familias $^{21}$. La causa, entonces, fue presentada inicialmente en el Juzgado de Artillería y el Auditor General de Guerra fue quien decidió el final del proceso. En el escrito con el que pretendía que le fuera admitida la querella, sostenía que el día en que fue agraviada estaba:

“retirándome yo á mi casa como á las ocho y media de la noche, á ocasión que dho mi marido se hallaba ausente en su tragin de conducir leña de los Montes de la otra 
vanda; quanto de improviso y estando yo á la puerta se llegó a mi la enunciada Nicolasa Correa improperandome en los términos más groseros so pretexto de que en la mañana del mismo dia había yo llamado al pulpero de la esquina de enfrente á fin de preguntarle lo que me ocurrio, siendo tal su atrevimiento que llegó hasta ponerme la mano, dándome una bofetada en la cara acompañándola con esta infame y denigrante expresión: grandísima P... ya se lo dire yo a su marido quando vuelva"22.

El caso trataba, entonces, de un conflicto entre dos mujeres cuyos maridos estaban transitoriamente ausentes por razones laborales -se encontraban trabajando fuera de la ciudad-, ambas vivían alquilando en cuartos contiguos en el Alto de San Pedro ${ }^{23}$ y compartían, por consiguiente, una red de relaciones barriales y sociabilidades de distinta naturaleza, que podían ir desde la solidaridad hasta el conflicto violento. Como ha señalado Arlette Farge, en estas sociedades "cara a cara" el barrio era un referente esencial e ineludible, una "encrucijada de reputaciones, fabricante de honras y deshonras" ${ }^{24}$, ya que el vecindario tenía no sólo la capacidad de escrutar y evaluar las reputaciones individuales o familiares; sino también la de transmitirlas, impugnarlas, o defenderlas cuando eran puestas en jaque.

El escrito del cual conservamos registro, muestra un razonable conocimiento del lenguaje del honor y de algunos de los tópicos que caracterizaban la presentación correcta de este tipo de juicios, aun cuando sea evidente que no fue redactado por la querellante y nos sea imposible determinar la autoría. En efecto, todas las presentaciones que se conservan en el expediente están escritas con la misma letra y figuran firmadas por Petrona Caldevilla que, en realidad, no sabía hacerlo:

"Quando una mujer casada vé ultrajado su honor de un modo tan vil y grosero; que otro recurso le puede quedar mas que el de acudir á los medios que las leyes ofrecen en semejantes casos? Con efecto, ellas señalan ciertas penas contra aquellas personas que con poco temor de Dios y de su conciencia tienen bastante libertad para emplear sus lenguas en descredito de las personas honradas con alguna expresión de las cinco que ellas mismas señalan, y siendo una de ellas la que la expresada Correa ha vertido en perjuicio de mi honor añadiendo á demás la (...) de darme una bofetada".

La mujer injuriada agregaba que "si semejantes excesos llegan á tolerarse se dejan sin castigo, esta indiferencia sea motivo ó pretexto para que ninguna persona honrada tenga seguro su honor y decoro en perjuicio de las buenas costumbres y ruina de la sociedad"25.

Sin embargo, este aparente conocimiento de la forma de sustanciar las causas -sin ser particularmente elaborado y por demás sintético en relación a la vaga mención que se hace de Las Partidas-, no se condice con las pruebas testimoniales aportadas para lograr un desenlace satisfactorio de la causa. La primera declaración testimonial es la de Don José Timoteo Silva, del mismo vecindario, quien sentado en la puerta de calle de su cuarto:

"vio salir de la Esquina inmediata a una Muger nombrada Nicolasa, a quien conoce la qual llegando a la casa de la Presentante Doña Petrona Caldevilla, le dio á esta una bofetada, y la trató de Puta, y habiendo esta improperado á aquella con igual expresión, se retiro la expresada Nicolasa á la Esquina de donde salio, en que vive" ${ }^{26}$.

17 Si el primer testimonio se revelaría inconveniente, porque pone en evidencia agravios verbales mutuos de idéntico tenor; el segundo, de Doña María de los Ángeles Espinosa, si bien confirma lo que se refiere en el escrito señalando que "sabe y le consta" que "es 
cierto", proviene de alguien conchabada con la querellante y es -asimismo- el último testigo aportado. En principio, que fueran solamente un par de declaraciones no era decisivo ni determinante para el curso del proceso, ya que dos testigos hábiles y coincidentes eran considerados una prueba suficiente, aunque -en general- se tendían a aportar más testimonios. Sin embargo aquí -más que una cuestión numérica- parece ser clave para la endeblez de la causa, la primera declaración, evidenciada en la atención que refleja el subrayado que se conserva en el original y que permite intuir hacia donde iba dirigiendo el foco de atención el escribano y/o quien juzgaba $y$, finalmente, dictaba la sentencia.

18 Por otro lado, al decidirse a dar inicio al pleito, Petrona (y seguramente quien la asesoraba y asistía en los aspectos procesales) no calculó que Nicolasa respondería intentando iniciar una contraquerella por injurias -que era una forma de reaccionar muy habitual en este tipo de juicios- contra su marido ${ }^{27}$, porque ambos le habrían gritado a ella misma "puta borracha" y el esposo de Petrona habría agregado el epíteto "cuchillera", además de haber amenazado vehementemente con golpearla. En el registro escrito de esta presentación consta que:

"estaban paradas á la puerta de su casa la mujer de Migolla y una china y le dixo la una á la otra; mujer mira esta, ya estará borracha y carcaxadas de risa á que le respondio la exponente, a quien Vmd trata de borracha y respondio a vos puta borracha, á que le contextó mas puta sois vosotras, y ellas se quedaron gritando puta borracha, puta borracha, mientras la exponente cerro la puerta y se retiro" ${ }^{28}$.

19 Es efectivamente probable que el tratar de iniciar la contraquerella, en principio contra el hombre, implicara un reconocimiento de la escasa posibilidad de éxito de hacerlo exclusivamente contra Petrona, ya que si bien ampliaba el agravio inicial recibido por ella misma en el intercambio y agregaba la burla -expresada en las risas, la sorna y la reiteración similar a un eco- que lo amplificaban, claramente estaba también reconociendo que los insultos fueron mutuos, aunque el suyo fuera presentado como una respuesta a la agresión recibida. Es así que se detendría en detallar los golpes y reiteradas amenazas recibidas, mientras negaba la bofetada que los testigos le adjudicaran, apelando a la inverosimilitud del gesto, debido a la mayor contextura física de la supuesta destinataria.

20 En esta línea, Nicolasa señalaba que cuatro días después del episodio, se le habría aparecido enfurecido el marido de Petrona, Migolla, insultándola nuevamente en idénticos términos, delante del pulpero Don Juan Testa y de dos soldados que lo contuvieron:

"y siempre tratándome de puta borracha que me lo havia de hacer bueno y que donde quiera que me encontrase me havia de patear y bofetear levantandome el testimonio de que le havia dado una guantada ásu mujer quando esta de manifiesto que es una mugerona, que me desaria entre sus manos (...) tratándome que era una cuchillera quando en ningún barrio de los que he vivido he tenido con persona alguna diferencia..." ${ }^{29}$.

21 La mujer agregaría también que su agresor, además de los insultos y amenazas, habría dado a entender que ella vivía en mala vida con el pulpero, cuando sería público y notorio que sólo vivía con su marido, sin darle la menor sospecha de una conducta indigna o indecente. El pulpero aparece mencionado por las dos mujeres -aunque la primera referencia es bastante opaca-, por lo que no es posible establecer con claridad el tipo de relación que mantenían, pero sí al menos la sospecha y la imputación, por 
ambas partes, de la existencia de un vínculo que -de existir- sería por completo inadecuado por el status matrimonial que poseían y ostentaban en los tribunales.

Es interesante señalar que la solicitud para iniciar una contraquerella se plantea muy rápidamente, lo cual da indicios de la circulación de información clave en el vecindario, del presumible tejido de solidaridades que se ponía en movimiento ante situaciones adversas y de cierta familiarización acerca de los procedimientos que convenía adoptar en estas circunstancias. Efectivamente, Nicolasa se enteró por algunos vecinos que Manuel Migolla y Petrona Caldevilla se habían querellado contra ella y habían ofrecido información de testigos, actitud que atribuía a un único objeto: encubrir las injurias verbales y reales que a ella le fueran destinadas.

Como hemos señalado en otros trabajos y como ha mostrado con claridad la historiografía ${ }^{30}$, los insultos de naturaleza sexual dirigidos a las mujeres dominaban ampliamente la semántica del agravio. El epíteto "puta" -reforzado o acompañado por otros términos o adjetivaciones- se encuentra presente en la mayoría de los pleitos, siendo desplegado tanto en conflictos con hombres como en altercados entre las mismas mujeres. Ahora bien, si atendemos al léxico específico ${ }^{31}$ que se utilizaba para expresar las ofensas y provocar el daño, es posible percibir una serie de combinaciones e imágenes que se asociaban para orientar o potenciar una significación que, sin dudas, era evidente para los destinatarios y espectadores, pero que presentaba connotaciones variadas. Aunque en este primer caso se registra inicialmente una contención pudorosa a la hora de poner por escrito el agravio, utilizando únicamente la inicial del insulto (P...), finalmente, las expresiones orales quedan registradas en forma detallada, si no por boca de la querellante, lo hacen los testigos en sus declaraciones.

En términos generales, el vocablo referido era una voz muy común para injuriar, que lógicamente aludía a la inmoralidad sexual y a la idea de transgresión asociada al pecado o a la indecencia. Asimismo, aunque no constan en este proceso puntual, también podían utilizarse en forma adicional o alternativa las expresiones "ramera", "prostituta" o "alcahueta". A esta última, tendía a asignársele un sentido de continuidad en el oficio y de trascendencia generacional, como una suerte de marca hereditaria que, a través del ejercicio de una actividad infame, se transmitía por la línea materna a las hijas. Por otro lado, la combinación con adjetivos y superlativos permitía profundizar la magnitud de la lascivia, la lujuria y el desenfreno ("grandísima Puta" o "reputa") y, en otras causas, el recurso retórico de la hipérbole redundaba en una exageración imposible de poner en práctica (como cuando se señalaba que era tan inmoral que había parido un centenar de hijos).

En menor medida, como muestra el expediente analizado, también se apelaba a la masculinización, al asociar la indecencia sexual con vicios y/o insultos destinados con mayor frecuencia a los hombres: "borracha y cuchillera". Los varones tildados de borrachos, aquellos que tenían fama de estar permanentemente ebrios, no eran dignos de crédito ni de respeto en los ámbitos de sociabilidad masculina, así como los que mostraban bastante rapidez y demasiada facilidad para sacar el cuchillo -por cualquier motivo, a ojos del entorno-, tampoco eran considerados fiables ${ }^{32}$. Este tipo de voces insultantes, ultrajantes y escandalosas, no agotaban por completo las potencialidades expresivas del insulto sexual, como veremos en el próximo caso.

El resultado del pleito fue insatisfactorio para ambas partes, ya que no se admitió la contraquerella y se les impuso perpetuo silencio ${ }^{33}$. Una mirada de alcance más general sobre estas causas muestra que, en aquellas ocasiones en que no hubo una agresión 
verbal y/o física unilateral, sino que las dos partes involucradas se insultaron y -luego de meditarlo- una de ellas decidió presentarse en el juzgado (como sucede en este caso, incoado 15 días después del hecho), generalmente se establecía que las ofensas habían sido mutuas, se las apercibía, eventualmente se imponía perpetuo silencio y se condenaba al pago compartido de las costas y, en ocasiones, al pago de multas por el escándalo. Por lo tanto, acudir a la justicia y obtener un resultado favorable, implicaba haber calculado previamente este tipo de riesgos, la "arreglada conducta" debía ser demostrable, no sólo declamada, y la información aportada por los testigos acerca del hecho puntual y de la pública voz y fama de las partes involucradas poseía una importancia insoslayable.

En la querella analizada, las mujeres involucradas fueron prevenidas muy seriamente:

"que si reincidiesen en iguales disenciones escandalosas tán opuestas á la honestidad y moderación que deben guardar, serán corregidas con la mayor severidad y aún puestas en reclusión por el término correspondiente quedando advertidas de que qualquiera de ambas Mugeres deberá trasladarse á vivir á otro barrio donde no las asista motivo de reiterar sus ofensas" ${ }^{34}$.

Evidentemente, para quien entendía en el pleito, éste no trataba del honor y la decencia, sino que mostraba precisamente lo contrario, una conducta opuesta a cualquier tipo de moderación, recato, decoro y honestidad. Si hacer justicia era la esencia del buen gobierno, y ésta era concebida como la perpetua y constante voluntad de dar a cada uno lo que es suyo, lo que el juez estaba determinando es que lo único que les correspondía a Petrona y a Nicolasa era un duro apercibimiento. Al mismo tiempo, se instaba a "hacer la prevención respectiva á sus Maridos, sin cuia licencia han instaurado sus querellas" ${ }^{35}$. No por ser una referencia aparentemente marginal, se trataba de una nota menor. Si bien se invocaba la ausencia de autorización de los esposos para sustanciar las causas, las dos mujeres habían hecho constar que contaban con la debida venia para iniciar los pleitos. Es probable que, estando los hombres fuera de la ciudad, se tratara simplemente de una referencia convencional y formularia, como parece suceder en muchos otros casos. Sin embargo, la prevención esbozada pareciera aludir a un aspecto que cobraba mayor relevancia por la ausencia física; la venia que suponían inexistente podría condensar así otros sentidos, del mismo modo que la advertencia: lo que tenían que controlar, remediar y corregir eran las conductas inapropiadas, indecentes, e indecorosas; siendo la corrección de las mujeres tanto una atribución como un deber y una responsabilidad masculina, no sólo estaban en falta aquí las mujeres -litigando por "quimeras"-, sino los hombres mismos, cuya falta de autoridad doméstica no podía ser más que reprobable y conducía así a endurecer las reconvenciones.

Este proceso muestra también una faceta mucho menos frecuente y una deriva no pensada del conflicto y de su judicialización, ya que por las continuas discordias una de las partes podía ser echada del barrio. La advertencia era muy significativa y dejaba sin márgenes de reclamo ni de judicialización futura a las partes; a los ruidosos escándalos reiterados oponía un silencio de naturaleza perpetua. La amenaza de la reclusión y la sombra del desalojo -para "cualquiera" -, equiparaban a ambas mujeres al considerar que no formaban parte de la "gente decente", al margen de cómo cada una de ellas se considerara y fuera percibida por los pares o por el entorno social de referencia. El hecho de que los términos de la resolución fueran notificados al Alcalde del cuartel donde habitaban, aumentaba los riesgos que podría implicar el intento de reiterar las ofensas. Aunque reclusión y expulsión eran dos prácticas claramente diferenciadas, 
compartían un punto central que, probablemente, explique la coexistencia de ambas figuras en el cierre del proceso: de un modo u otro remitían a la posibilidad de apartarlas de la comunidad, una comunidad barrial pequeña, pero que formaba parte en definitiva de un universo mayor, inserto en una matriz religiosa católica y en un orden político, jurídico y social, que valoraba especialmente la conciliación, la armonía, el sosiego, la quietud y la concordia entre los vecinos. Esos valores centrales eran precisamente- los que se invocaban en otros casos, en los que intervenían terceros personas de carácter y celosos de la paz- para mediar y conciliar entre las partes enfrentadas y que conducían a desistimientos de continuar con pleitos que, además de complejos por acarrear desazones, eran costosos.

\section{Dolores y Ana: la judicialización paralela para hacer frente al desalojo}

30 Si bien, como hemos señalado, la defensa del honor mancillado actuaba como eje estructurador del planteamiento de este tipo de causas, acudir a los tribunales podía tener un objetivo que se revelaría estratégico en otro sentido, reflejado incluso en la evaluación de en qué juzgado convenía tramitar el pleito.

31 La justicia en primera instancia descansaba en jueces legos -los vecinos de la ciudad-, a través del cabildo y de su expresión jurisdiccional: los alcaldes ordinarios ${ }^{36}$. Cuando Doña Dolores Gómez (mujer de Don Manuel Piagudo) presentó una querella por injurias verbales y reales contra Doña Ana Márquez y su marido Francisco Morella, decidió hacerlo expresamente en el juzgado de $1 \mathrm{er}$ voto $^{37}$. En la presentación del caso señaló que estando uno de sus hijos de apenas tres años jugando en la calle, sin otro motivo que haber hecho un poco de ruido, su vecina Ana -que también alquilaba un cuarto al lado del suyo en el Barrio de La Piedad- le dio una bofetada. En cuanto ella se dirigió a averiguar lo que sucedía, alertada por el llanto del niño, ésta le respondió furiosa, con improperios e insultos: "si si yo le he pegado grandísima Puta obeja", mientras el marido de la acusada la llenó de agravios ultrajantes en el mismo sentido, "si yo también telo digo grandísima Puta y reputa yo no te he querido montar que te monte mi caballo" ${ }^{38}$.

Efectivamente, como Dolores haría constar en su escrito, "son expresiones bastante indecorosas y obsenas que deben taparse los oidos para no oírlas, pero es preciso vertirlas en testimonio de la verdad" ${ }^{39}$. Al salir a la calle Manuel -el esposo de la ofendida- para pedir que se contuviesen, Morella le asestó además un fuerte golpe con un rebenque provocándole una contusión que - como veremos- sería luego constatada por el Alcalde de Barrio.

33 En la causa iniciada por Dolores, se evidencia un conocimiento de las posibilidades que podía abrir el recurso judicial, así como la búsqueda de un asesoramiento y acompañamiento letrado que le permitiera el dominio de la retórica adecuada para presentar el delito:

"No pueden verse otras injurias mas atroces é infamatorias que estas, dignas de ser enteramente resarcidas en todo rigor de justicia. Ellas han herido gravemente el honor y reputación de una esposa honesta y honrrada que jamas ha dado la mas leve nota de su conducta, ni margen para que su composición sea infamada con escandalo publico por individuos a quienes jamas ha agraviado en la minima cosa" ${ }^{40}$. 

asignación a las mujeres del uso de una serie de expresiones, unos gestos, unos modos y una violencia, que no se consideraban apropiadas para el género y para la interacción social, y que remiten -asimismo- a otras concepciones del comportamiento indecente e indisciplinado ${ }^{43}$. 
39 A diferencia del caso anterior, Dolores presentó seis testigos, todos del barrio -que presenciaron el roce desde las ventanas, las puertas de las casas, la calle o la pulpería-, y que declararon sin aportar más datos pero, en general, de acuerdo con el escrito presentado al inicio de la querella. En vistas de la información producida, procedió a pedir al Alcalde un elevado resarcimiento económico y que la parte contraria se hiciera cargo de las costas, solicitando el embargo de bienes y la prisión de Morella, dado que estarían

“plenamente comprobadas y patentes según la depocision unánime delos testigos presentados. No ignorará VS que la ley de partida hablando de injurias verbales trata de ser una de ella en tratarse á una persona de Puta, y siendo casada y honrrada acrese" ${ }^{\prime 4}$.

Al referirse a los vecinos, Dolores señalaba que eran:

"unas personas insultadoras que a cada paso me provocan con dicterios que una mujer de mi clase no merese por lo que asi mismo pido se lleve á debido efecto el desalojo que se ha librado por el Alcalde de Barrio y que se confirmó por el $\mathrm{Sr}$ Alcalde de 2do voto..." ${ }^{45}$.

41 Es recién en esta instancia que aparece mencionado un aspecto central y hasta entonces explícitamente eludido, el problema del desalojo (que la querellante pedía para Francisco Morella y Ana Márquez). Por esta razón, el Alcalde de 1er voto -que venía llevando la causa-, decide pasar el expediente al de 2 do voto, porque es el que había tenido conocimiento y tomado disposiciones previas en relación con las desavenencias entre las dos familias.

42 A partir de la notificación de dicha providencia, Dolores rechazaría el traslado con tenacidad e insistiría en que el Juzgado de 2do voto era completamente ajeno a esta querella en particular "y solo si atento á un desalojo de mi referido Esposo por una querella de Morella (...) porque una cosa es desalojo sin citación de parte y otra es la querella que tengo puesta por venir á ser la parte agraviada". Es así que, de modo confuso, comienza a vislumbrarse que el desalojo también afectaba a su propia familia.

Al estimar que el traslado le resultaba gravoso y perjudicial, solicitó un recurso de apelación. En las argumentaciones subsiguientes se van iluminando algunos aspectos del conflicto. El día de la pelea, el Alcalde de Barrio había citado a los dos hombres para esclarecer el asunto y mandó desalojar a Morella, pero como éste se quejara ante el Alcalde de 2 do voto, el último dispuso entonces el desalojo para ambos, ante lo cual el marido de Dolores interpuso una queja porque a él no se lo había citado ni oído. Se entiende, entonces, con mayor claridad, la decisión de la mujer de no presentar esta causa en aquel juzgado:

"¿Qué tengo yo Sr que ver con el desalojo?; ¿yo por ventura intervine en el Juicio que se tubo ante el Alcalde de Barrio?; ¿se me citó para alguna cosa por el Juzgado de 2 do voto?; $i$ entonces que motivo legal hay para que se pase el conocimiento de mi querella al Juzgado de 2do voto?; ¿No soy la principalmente agraviada?; ¿Por ventura no soy yo libre para escoger el Juzgado que quiera?; ¿y por que pues se me compele á que prosiga mi querella en el Juzgado de segundo voto y maxime, quando el Juez por lo hecho con mi esposo viene á ser en alguna manera sospechoso? (ablo con el decoro debido al Juzgado)" ${ }^{46}$.

La querella prosiguió en manos del Alcalde de 1er voto, revocándose el auto de traslado, ante el cual se vio obligado a presentar un escrito de respuesta la parte contraria -Don Francisco Morella-, señalando en esa instancia "que todo el tenor de lo producido solo sirve á instruirme, quan empeñado está mi contrario en evadirse del desalojo, y demás 
penas que tengo pedidas ante el Juzgado de 2do voto a que se ha hecho abundantemente acrehedor" ${ }^{47}$.

Como queda en evidencia, nuevamente, la circulación de información y rumores era habitual en el vecindario e, incluso, podría considerarse también como un recurso a disposición de las partes, ya que Morella tenía "extrajudicial noticia" antes de que se le notificara oficialmente y pudiera ver el expediente de la causa iniciada en su contra: "aunque jamas crehi llegase Dolores Gomes al extremo de vindicar honestidad, á darse por agraviada de palabras lacivas; quando como á Andaluza desaforada jamas le há conocido nadie". Naturalmente, se oponía a tratar el problema como causas separadas, señalando que no había otro motivo para la demanda que planteaban que evitar el desalojo y esperaba que se castigara:

"la impudicia, la liviandad, la desvergüenza y ese escandaloso desorden que caracterizan a la Gomes y que ofende los oydos mas impuros, y que jamas há sabido corregir su marido Piagudo (...) En consecuencia VS debe conocer que la Gomes combinada con su marido no há procurado sino la justificación de VS con una demanda posterior a la que (...) se hallaba entablada en el Juzgado de 2do voto..." ${ }^{\prime 4}$.

Si Dolores era presentada como una mujer impúdica y desvergonzada ${ }^{49}$, su marido -al ser considerado incapaz de corregirla- también veía menoscabada una dimensión de la hombría, no ya relacionada con el control de la sexualidad de las mujeres, sino con la capacidad y el deber patriarcal de guiar y corregir las conductas indisciplinadas.

Este punto presenta similitudes con el caso anterior, aunque aquí la incapacidad masculina no se refiere de manera velada sino de forma muy explícita; se trata además de una imputación entre pares y no de una advertencia de las autoridades. Sin embargo, a pesar de las diferencias, los indicios muestran que comparten la firme convicción cultural de que la corrección o el disciplinamiento eran no sólo un derecho o una prerrogativa, sino una responsabilidad de los esposos, cuya autoridad se consideraba conferida por leyes divinas y naturales. Dicha autoridad masculina marital y paternal- debía garantizar la subordinación y la obediencia de la mujer y de los hijos (en el caso de las familias de la élite, también de la servidumbre y esclavos), que debían estar basadas no tanto en el temor, sino en el amor y el respeto. El recurso al castigo doméstico, para enderezar conductas percibidas como desviadas, era entendido y explicado como una fraternal corrección ${ }^{50}$.

La estrategia seguida por Morella, además de desacreditar a sus querellantes, apuntaba a fortalecer la idea de la falsedad y la clandestinidad de la causa en su contra, señalando que esto mismo se encontraría probado por once declaraciones testimoniales que oportunamente presentara en el Juzgado de 2 do voto. Es que luego de haber sido expulsados del barrio ambos matrimonios por las continuas discordias, él había procedido a solicitar la revocación de la expulsión decretada, ofreciendo información sumaria de la buena conducta de su familia y de la escandalosa que caracterizaría a sus contrarios:

"negando yo la bofetada como falsa, y de mero pretesto para la discordia me hé quexado al Juzgado de 2 do voto de su voracidad, y escándalos consiguientes con que no aparese otro motivo para haber llevado mis contrarios la demanda ante VS que ver forma de escapar el desalojo sorprehendiendolo. Esta misma acumulación indicando iguales fundamentos tengo pedida ante el Alcalde de 2 do voto á virtud de la plena información con que hé comprobado la indignidad y maledicencia en todos sentidos de la Gomes, y su marido en aquel Barrio; lo que igualmente me dispensa de deslindar ante VS la mala fe, y peor carácter de los declarantes conque la Gomes ha organisado su sumario..." ${ }^{51}$. 
cercanías y afinidades. Como ha señalado Farge,

"se ha borrado la densidad de los gritos, efímeros pero violentos; los sonidos de la injuria han cesado, pero cada uno, carnalmente, carga con la situación conflictiva a la que ha asistido, la recuerda, lleva sus palabras a otra parte y de otra forma, para otros usos (...). El recuerdo oral y sonoro de las discusiones es, al menos, un mantillo particular sobre el que se adhieren tanto gestos solidarios como odios repentinos" 52 .

Entran a jugar aquí tanto las tensiones evidentes en el marco de la conflictividad vecinal, ligadas a roces por los límites, los ruidos, la conducta de los hijos, etc., como la existencia de una serie de solidaridades que pueden ponerse en marcha en los distintos tipos de declaraciones testimoniales reunidas por ambas partes. Morella no sólo criticaba la judicialización que llevaba adelante Dolores, sino que apuntaba a la mala fe y carácter de los testigos presentados, a los que definía como gente de "su parcialidad", mientras él mismo había reunido un grupo numeroso que habría declarado a favor de su familia. Como señala María Eugenia Albornoz, una vez más se evidencia que "los miembros de la comunidad son gestores, actores y receptores del escándalo, y por medio de sus sentidos conocen, responden y replican"53.

51 Este expediente muestra la intervención decisiva de una figura, apenas mencionada en el caso anterior -donde se le notificaba el resultado de lo actuado-, que es la del Alcalde de Barrio ${ }^{54}$. Dentro de las variadas tareas que se les conferían a los individuos que asumían esta carga honorífica, nos interesa en especial -para los fines de este artículodetenernos en una de sus funciones, como oficiales de baja justicia con jurisdicción delegada ${ }^{55}$. Elegidos entre los vecinos respetables y honrados, estos individuos eran naturalmente- miembros plenos de esa pequeña comunidad, que debían vigilar con celo la pureza de las costumbres, las conductas, las ofensas a Dios y los pecados públicos, así como las muertes, robos y heridas; tenían así la capacidad de prender in fraganti y de intervenir y componer en desavenencias y/o riñas menores, en pos de garantizar la paz, la quietud y la seguridad ${ }^{56}$. Esta atención vigilante, sin embargo, debía guiarse por la prudencia, ya que no debían "proceder por delaciones arbitrarias ni mezclarse en las interioridades de las familias y su gobierno económico, despreciando las denuncias de delitos indeterminados y teniendo particular atención a la calidad de la persona del denunciante" ${ }^{57}$. Si el ámbito de la conflictividad casera y doméstica les estaba vedado, su intervención era decisiva en los casos de comportamiento público de naturaleza escandalosa, como el que caracterizaba a este segundo pleito y que había conducido al desalojo de las partes enfrentadas. Esta expulsión -que efectivamente sería cuestionada y resistida- sólo podía decidirla en el estrecho territorio de su andar a pie, es decir, en las escasas cuadras donde poseía jurisdicción.

Enmarcado en ese cuestionamiento, el reclamo elevado por Morella se reveló efectivo, ya que al contar con esa información adicional, se decidió que la causa fuera seguida, finalmente, por el Juzgado de 2do voto. La querella está inconclusa, no disponemos por el momento de información adicional y no podemos establecer si el desalojo ordenado se llevó a afecto, pero el expediente muestra de manera elocuente el uso táctico de la justicia, en un sentido que incluye una calculada disputa por el juzgado ante el cual llevar adelante el pleito, atendiendo a una serie de expectativas que podrían favorecer el desenlace del mismo-por ambas partes- y que trasciende el problema del honor invocado al principio, aunque se exprese inicialmente en ese lenguaje, que era -en definitiva- la forma adecuada de iniciar y presentar los juicios. Las estrategias 
perseguidas podían ser variables y, en este sentido, es posible pensar en un abanico de opciones que van desde cuestionar, resistir y evitar el desalojo de la propia familia, esperar que el mismo afecte a la parte contraria o bien, dada la gravedad del caso, lograr dilatarlo o demorarlo.

\section{Consideraciones finales}

53 La arena judicial puede ser concebida -en principio- como un ámbito no sólo de expresión de un conflicto entre las partes enfrentadas o un escenario más (entre otros) de búsqueda de una solución (aunque fuera transitoria), sino también como un espacio de definición, impugnación, disputa y negociación de las identidades sociales, familiares y de género. En esta línea, es posible resaltar que este tipo de causas no sólo ofrecen una ventana para acceder a mecanismos informales de clasificación y de denigración social -como los insultos, los gestos o las actitudes violentas-, sino también a otros recursos más sutiles -pero insoslayables para la época- como la asignación o no del tratamiento de Doña/Don y otras formas en que son aludidas las partes enfrentadas. Algunos autores han señalado que el uso del Don era un signo de prestigio y de reconocimiento social y que su utilización era fuertemente situacional, incidiendo en el otorgamiento factores como la ascendencia (no se le asignaba a las castas), la ocupación, la capacidad económica, las relaciones personales y la reputación, de modo tal que un individuo podía ser Don para sus vecinos (o, al menos, para algunos de ellos) pero no así para la élite o para las autoridades ${ }^{58}$. En el primer caso, si bien Petrona se antepone el Doña y a lo largo del documento todas las referencias a su persona lo incluyen, no sucede lo mismo con Nicolasa, que se lo asigna únicamente ella. En el segundo caso, si en los inicios de los escritos el Doña/Don son registrados, no se repite en las sucesivas menciones y las partes recurren con más frecuencia a otras formas de referirse a los contrarios, como "andaluza desaforada" o "la Gómez", siendo todos éstos claros indicios del escaso respeto y consideración que estiman que merecen y que se hace explícita -como hemos visto- también por otros medios (por ejemplo, las once declaraciones testimoniales que consiguiera Morella).

En segundo lugar, el papel de los vecinos del barrio es central en este tipo de causas (y en todas aquellas en las que sean requeridos como testigos $\mathrm{y}$, por ende, tengan incidencia probatoria) porque -más allá de permitir rastrear sociabilidades, solidaridades, afinidades, parcialidades y tensiones barriales- cumplen un papel determinante en relación con el problema de la reputación de las familias enfrentadas. De este modo, es fundamental subrayar la importancia del tipo de declaraciones testimoniales que brindan, tanto sobre el asunto puntual que se denuncia confirmando, matizando o relativizando los hechos-, como cuando dan cuenta de la pública voz y fama de los involucrados (ya sea defendiendo la arreglada conducta o aportando información sobre el atrevimiento, el mal carácter o los escandalosos procederes). Asimismo, se pueden inferir sus voces a través de la circulación de los rumores y de la información extrajudicial, al punto que deben ser consideradas como un recurso adicional, valioso y disponible para las partes litigantes. Como hemos visto, los querellados se enteran informalmente del inicio de la causa iniciada en su contra antes de la notificación oficial, lo que les amplía el margen para pensar o averiguar de qué modo es oportuno y conveniente proceder ante la inminencia de la requisitoria judicial. 
Por otro lado, en relación con el problema de la cultura jurídica y judicial que demuestran los diferentes actores involucrados en los procesos, se evidencia que estos pleiteantes decididos, enredados en litigios contenciosos, inmersos en los ámbitos del fuero militar, de la justicia capitular ordinaria o de las bajas justicias de las alcaldías de barrio, exigieron justicia motivados por diversas lógicas y, en cada una de las acciones perseguidas, es posible detectar la circulación de algunos saberes fragmentarios vinculados a las leyes, a los delitos y a algunos aspectos procesales. Como ha mostrado con agudeza Darío Barriera, los expedientes "abrigan corredores por donde a través de unos lenguajes se comunican -(...) de manera desigual, asimétrica- los universos culturales de letrados y legos" ${ }^{59}$, ya que si efectivamente los legos conocen cosas que provienen de un universo letrado, los letrados también apelaban a saberes populares o del común. El autor entiende a la cultura judicial como "un conjunto de saberes (teóricos, técnicos y prácticos) que implicaban todo el saber hacer en la situación judicial" 60 . En esta línea, desde el punto de vista de los litigantes, consideramos que efectivamente ya fuera por experiencia propia o por compartir las experiencias del entorno, lograban dominar ciertas competencias aunque fuera de forma rudimentaria. De este modo, es posible señalar que el hecho de haber pleiteado antes o de haber sido citados como testigos, constituían seguramente buenos aprendizajes, saber que otros lo hacían y de qué modo se habían conducido también, ya que en las declaraciones testimoniales -en las que se veía involucrado un universo social sumamente heterogéneo- se aprendía la práctica del juramento, se los interrogaba con arreglo al escrito que daba inicio a la querella o, también, de acuerdo a una serie de preguntas previamente establecidas, y se les leían las declaraciones para la posterior ratificación y firma (en el caso de poder hacerlo). Este aprendizaje era inestimable, ya que ninguno de los individuos involucrados en los casos analizados sabía leer y escribir. El conocimiento adquirido circulaba en el entorno, así se enteraban y se difundían cuestiones vinculadas a las causas y, lógicamente, buscaban la ayuda necesaria para moverse de la manera -que creían o les sugerían- que era la más conveniente.

Para concluir, la relación entre injurias, justicias y desalojos que recorrimos en este trabajo, no se presenta de un modo lineal y aquí reside una diferencia significativa que también explica la elección de estos dos expedientes. En este sentido, el desalojo puede ser entendido como el punto de llegada de una querella judicial que se ha revelado inconducente, sin posibilidades de prosperar adecuadamente por la endeblez de la causa y por las respuestas desplegadas por la parte contraria, lo que evidencia la distancia entre expectativas y resultados a la hora de requerir la intervención judicial. Sin embargo, como hemos visto, el desalojo puede ser también el punto de partida y el planteamiento de la querella ser concebida así, y más allá del grado de éxito finalmente obtenido, como un modo estratégico de evitarlo.

\section{Fuentes primarias}

Archivo General de la Nación, Buenos Aires, Argentina, Tribunales Criminales 1752-1825, Legajo M número 1 (1819).

Archivo General de la Nación, Buenos Aires, Argentina, Tribunales Criminales 1756-1827, Legajo C número 1, Expediente 9 (1805). 


\section{BIBLIOGRAFÍA}

Agüero, Alejandro, "Las categorías básicas de la cultura jurisdiccional” en Lorente Sariñena, Marta (coord.), De justicia de jueces a Justicia de leyes: Hacia la España de 1870, Consejo General del Poder Judicial, Madrid, 2007.

Agüero, Alejandro, Castigar y perdonar cuando conviene a la República. La justicia penal de Córdoba del Tucumán, siglos XVII y XVIII, Centro de Estudios políticos y constitucionales, Madrid, 2008.

Albornoz Vásquez, María Eugenia \& Argouse, Aude, "Mencionar y tratar el cuerpo: indígenas, mujeres y categorías jurídicas. Violencias del orden hispano colonial, Virreinato del Perú, s. XVIIXVIII", Nuevo Mundo Mundos Nuevos, n9, 2009, http://nuevomundo.revues.org/53163, consultado el 28 de mayo de 2011.

Albornoz Vásquez, María Eugenia, “Umbrales sensibles de la modernidad temprana: los usos de la vergüenza en Chile, siglos XVIII y XIX”, Nuevo Mundo Mundos Nuevos, n9, 2009, http:// nuevomundo.revues.org/5565, consultado el 14 de diciembre de 2011.

Albornoz Vásquez, María Eugenia, "El mandato de silencio perpetuo. Existencia, escritura y olvido de conflictos cotidianos. Chile, 1720-1840" en Cornejo, Tomás \& González, Carolina (dir.), Justicia, poder y sociedad: recorridos históricos. Chile, s. XVIII-XXI, Ed. Universidad Diego Portales, Santiago de Chile, 2007.

Albornoz Vásquez, María Eugenia, "El precio de los cuerpos maltratados: discursos judiciales para comprar la memoria de las marcas de dolor. Chile, 1773-1813", Nuevo Mundo Mundos Nuevos, n9, 2009, http://nuevomundo.revues.org/55888, consultado el 19 de noviembre de 2011.

Albornoz Vásquez, María Eugenia, “La injuria de Palabra en Santiago de Chile, 1672-1822”, Nuevo Mundo Mundos Nuevos, ${ }^{\circ} 4,2004$, http://nuevomundo.revues.org/240, consultado el 15 de abril de 2006.

Albornoz Vásquez, María Eugenia, "Sufrimientos individuales declinados en plural. La necesaria singularidad de los pelitos por injurias en Hispanoamérica colonial”, Dossier coordinado por Langue, Frédérique \& Vidal, Edgar, "Histoire culturelle et histoireurbaine: hommage à Sandra Jatahy Pesavento", en Nuevo Mundo Mundos Nuevos, n¹0, 2010, http://nuevomundo.revues.org/ 60138, consultado el 10 de abril de 2012.

Albornoz Vásquez, María Eugenia, “Calidades, colores y vergüenzas. Cuerpos, sentimientos y tensiones sociales en Chile (1672-1874), Revista del Archivo Nacional de Chile, Santiago de Chile, $\mathrm{n}^{\circ} 4$, 2007.

Albornoz Vásquez, María Eugenia, “Casos de corte y privilegios de pobreza: lenguajes jurídicos coloniales y republicanos para el rescate de derechos especiales en el momento de litigar por injurias. Chile, 1700-1874", Signos Históricos, México, n³2, 2014.

Araya Espinosa, Alejandra, "La pureza y la carne: el cuerpo de las mujeres en el imaginario político de la sociedad colonial”, Revista de Historia social y de las Mentalidades, Santiago de Chile, Año VIII, vol. 1/ 2, 2004.

Barriera, Darío (coord.), La justicia y las formas de la autoridad, ISHIR CONICET - Red Columnaria, Rosario, 2010.

Barriera, Darío, Justicias situadas. Instituciones, agentes, culturas y espacios (entre el Virreinato Rioplatense y la República Argentina), Ediciones de la UNLP, Buenos Aires, 2018. 
Barriera, Darío, “El alcalde de barrio, de justicia a policía (Río de la Plata, 1770-1830)”, Nuevo Mundo Mundos Nuevos, 2017, http://journals.openedition.org/nuevomundo/70602, consultado el 19 de octubre de 2017.

Barriera, Darío, "Lenguajes y saberes judiciales de los legos en el Río de la Plata (siglos XVI-XIX)” en Sozzo, Máximo (coord.), Historias de la cuestión criminal en la Argentina, Ed. Del Puerto, Buenos Aires, 2009.

Barriera, Darío, "La ciudad y las varas: justicia, justicias y jurisdicciones (ss. XVI-XVII), Revista de Historia del Derecho, $n^{\circ} 31$, Instituto de Investigaciones de Historia del Derecho, Buenos Aires, 2003.

Brangier, Víctor \& Barriera, Darío, “Lenguajes comunes en 'Justicias de jueces'. Tratamientos historiográficos y fondos judiciales en Chile y Argentina", Revista de Humanidades, Sevilla, n³2, 2015.

Burke, Peter, Hablar y callar. Funciones del lenguaje a través de la historia, Gedisa, Barcelona, 1996.

Cañeque, Alejandro, “Cultura vicerregia y Estado Colonial. Una aproximación crítica al estudio de la historia política de la Nueva España”, Historia Mexicana, México, vol. LI, n¹, 2001.

Casagrande, Agustín, "Por una historia conceptual de la Seguridad. Los Alcaldes de Barrio de la Ciudad de Buenos Aires (1770-1820), Conceptos Históricos, Buenos Aires, n¹, p. 40-71.

Cicerchia, Ricardo, "De mujeres, varones y jueces. Familia popular y justicia en la ciudad de Buenos Aires (1777-1850)" en Perrin, Michel \& Perruchon, Marie (comp.), Complementariedad entre hombre y mujer. Relaciones de género desde la perspectiva amerindia, ABYA-YALA, Quito, 1997.

Di Meglio, Gabriel, ¡Viva el bajo pueblo! La plebe urbana de Buenos Aires y la política entre la Revolución de Mayo y el Rosismo, Prometeo, Buenos Aires, 2007.

Farge, Arlette, Efusión y tormento. El relato de los cuerpos. Historia del pueblo en el siglo XVIII, Katz Editores, Madrid, 2008.

Farge, Arlette, La vida frágil. Violencia, poderes y solidaridades en el París del siglo XVIII, Instituto Mora, México, 1994.

Fernández, María Alejandra, "Defender, negociar y disputar la identidad: las representaciones femeninas en la arena judicial (Buenos Aires, fines del siglo XVIII- principios del s. XIX)", Ponencia presentada en las XIII Jornadas nacionales de Historia de las mujeres y VIII Congreso Iberoamericano de Estudios de género, FFyL-UBA/FSOC-UBA/UNQ, 24, 25, 26 y 27 de Julio de 2017.

Fernández, María Alejandra, "Reputaciones masculinas y definiciones socioculturales de la hombría. Buenos Aires, 1750-1810”, Temas Americanistas, n³7, 2016,http://institucional.us.es/ tamericanistas/index.php?page=numero-37.

Fernández, María Alejandra, Honor e insultos. Buenos Aires, 1750-1820, Tesis de doctorado en Historia, Universidad de Buenos Aires, Buenos Aires, Argentina, 2014.

Fernández, María Alejandra, “A propósito de las injurias: una aproximación a los usos de la justicia colonial en Buenos Aires, 1750-1810" en Mallo, Silvia \& Moreyra, Beatriz (coord.), Miradas sobre la historia social en la Argentina en los comienzos del siglo XXI, Centro de Estudios Históricos "Prof. C. Segreti”, Instituto de Historia Americana Colonial UNLP, Córdoba, 2008.

Fradkin, Raúl (comp.), 'La ley es tela de araña'. Ley, justicia y sociedad rural en Buenos Aires, 1780-1830, Prometeo, Buenos Aires, 2009.

Fradkin, Raúl, El poder y la vara. Estudios sobre la justicia y la construcción del Estado en el Buenos Aires rural, Prometeo, Buenos Aires, 2007. 
Garriga, Carlos, “Orden jurídico y poder político en el Antiguo Régimen”, ISTOR: Revista de Historia Internacional, México, año IV, n¹6, 2004.

Garriga, Carlos, "Sobre el gobierno de la justicia en Indias (siglos XVI-XVII)", Revista de Historia del Derecho, n³4, Buenos Aires, 2006.

Garrioch, David, Neighbourhood \& Community in Paris, 1740-1790, Cambridge University Press, Cambridge, 1986.

Ghirardi, Mónica, "Familia y maltrato doméstico. Audiencia episcopal de Córdoba, Argentina. 1700-1850”, Revista Historia Unisinos, vol. 12, n¹, Río de Janeiro, 2008.

Gowing, Laura, Domestic Dangers. Women, Words, and Sex in Early Modern London, Oxford University Press, Oxford, 1996.

Halperin Donghi, Tulio, Reforma y disolución de los imperios ibéricos, Alianza, Madrid, 1985.

Hanger, Kimberly, "Introduction. Words and Deeds: Racial and gender dialogue, Identity, and conflict in the Viceroyalty of New Spain”, The Americas, Cambridge, vol. 54, n4, 1998.

Hespanha, Antonio, La gracia del derecho. Economía de la cultura en la Edad Moderna, Centro de Estudios Constitucionales, Madrid, 1993.

Johnson, Lyman \& Lipsett-Rivera, Sonya (eds.), The Faces of Honor. Sex, Shame and Violence in Colonial Latin America, University of New Mexico Press, Albuquerque 1998.

Johnson, Lyman \& Socolow, Susan, "Población y espacio en el Buenos Aires del siglo XVIII", Desarrollo Económico, Buenos Aires, vol. 20, nำ9, 1980.

Johnson, Lyman, Workshop of Revolution. Plebeian Buenos Aires and the Atlantic World, 1776-1810, Duke University Press, Durham and London, 2011.

Lipsett-Rivera, Sonya, "De Obra y Palabra: Patterns of insults in Mexico, 1750-1856", The Americas, Cambridge, vol. 54, n4, 1998.

Lipsett-Rivera, Sonya, "Honor, familia y violencia en México" en Gonzalbo Aizpuru, Pilar \& Zárate Toscano, Verónica (coord.), Gozos y sufrimientos en la Historia de México, El Colegio de MéxicoInstituto Mora, México, 2007.

Lipsett-Rivera, Sonya, "Los insultos en la Nueva España en el siglo XVIII" en Gonzalbo Aizpuru, Pilar (dir.), Historia de la vida cotidiana en México, tomo III El siglo XVIII, entre tradición y cambio, El Colegio de México- FCE, México, 2005.

Madero, Marta, Manos violentas, palabras vedadas. La injuria en Castilla y León (siglos XIII-XV), Taurus Humanidades, Madrid, 1992.

Mallo, Silvia, "Hombres, Mujeres y Honor. Injurias, calumnias y difamación en Buenos. Aires. (1770-1840). Un aspecto de la mentalidad vigente”, Estudios de Historia colonial, Buenos Aires, n¹3, 1993.

Mallo, Silvia, La sociedad rioplatense ante la justicia. La transición del siglo XVIII al XIX, Publicaciones del AHPBA, Buenos Aires, 2004.

Martin, Cheryl, "Popular Speech and Social Order in Northern Mexico, 1650-1830", Comparative Studies in Society and History, Cambridge, vol. 32, $\mathrm{n}^{\circ} 2,1990$.

Owensby, Brian, "Pacto entre Rey lejano y súbditos indígenas: justicia, legalidad y política en Nueva España, siglo XVII”, Historia Mexicana, México, volumen LXI, n¹, 2011. 
Palacio, Juan Manuel \& Candioti, Magdalena (comp.), Justicia, política y derechos en América Latina, Prometeo, Buenos Aires, 2007.

Pérez, Mariana, En busca de mejor fortuna. Los inmigrantes españoles en Buenos Aires desde el Virreinato a la Revolución de Mayo, Prometeo, Buenos Aires, 2010.

Perry, Mary Elizabeth, Gender and Disorder in Early Modern Seville, Princeton University Press, New Jersey, 1990.

Quinteros, Guillermo, La política del matrimonio. Novios, amantes y familias ante la justicia, Buenos Aires, 1776-1860, Prohistoria, Rosario, 2015.

Rebagliati, Lucas, "Los pobres ante la justicia: discursos, prácticas y estrategias de subsistencia en Buenos Aires (1785-1821)", Boletín del Instituto de Historia Argentina y Americana Dr. Emilio Ravignani, Buenos Aires, n³8, 2013.

Serulnikov, Sergio, “'Su verdad y su justicia'. Tomás Catari y la insurrección aymara de Chayanta, 1777-1780" en Walker, Charles (comp.), Entre la retórica y la insurgencia: las ideas y los movimientos sociales en los Andes, Siglo XVIII, Centro de Estudios regionales Andinos 'Bartolomé de Las Casas', Cusco, 1996.

Serulnikov, Sergio, Conflictos sociales e insurrección en el mundo colonial andino. El norte de Potosí en el siglo XVIII, FCE, Buenos Aires, 2006.

Stern, Steve, Los pueblos indígenas del Perú y el desafío de la conquista española, Alianza, Madrid, 1986.

Twinam, Ann, Vidas públicas, secretos privados. Género, honor, sexualidad e ilegitimidad en la Hispanoamérica colonial, FCE, Buenos Aires, 2009.

Undurraga Schüler, Verónica, "Honores transversales, honores polisémicos en la sociedad chilena del siglo XVIII" en Araya, Alejandra \& Candina Azun \& Cussen Celia (coord.), Del Nuevo al Viejo Mundo: Mentalidades y representaciones desde América, Fondo de Publicaciones Americanistas y Facultad de Humanidades de la Universidad de Chile, Santiago de Chile, 2008.

Undurraga Schüler, Verónica, Los rostros del honor, Dibam Ediciones, Santiago de Chile, 2012.

Undurraga Schüler, Verónica, "Españoles oscuros y mulatos blancos: identidades múltiples y disfraces del color en el ocaso de la colonia chilena. 1778-1820" en Gaune, Rafael \& Lara, Martín (coord.), Historias de racismo y discriminación en Chile, Uq-Bar, Santiago de Chile, 2010.

Vassallo, Jaqueline, Mujeres delincuentes. Una mirada de género en la Córdoba del siglo XVIII, UNC, Córdoba, 2006.

Zamora, Romina, Casa poblada y buen gobierno: oeconomia católica y servicio personal en San Miguel de Tucumán, siglo XVIII, Prometeo, Buenos Aires, 2017.

\section{NOTAS}

1. La referencia pionera e insoslayable es el trabajo de Madero, Marta, Manos violentas, palabras vedadas. La injuria en Castilla y León (siglos XIII-XV), Taurus Humanidades, Madrid, 1992. Para Hispanoamérica, ver Mallo, Silvia, "Hombres, Mujeres y Honor. Injurias, calumnias y difamación en Buenos. Aires. (1770-1840). Un aspecto de la mentalidad vigente”, Estudios de Historia colonial, Buenos Aires, $n^{\circ} 13,1993$. Martin, Cheryl, "Popular Speech and Social Order in Northern Mexico, 1650-1830", Comparative Studies in Society and History, Cambridge, vol. 32, n², 1990. Hanger, Kimberly, "Introduction. Words and Deeds: Racial and gender dialogue, Identity, and conflict in the Viceroyalty of New Spain", The Americas, Cambridge, vol. 54, n 1998. 
2. Para aproximaciones desde la historia social del lenguaje, ver Burke, Peter, Hablar y callar. Funciones del lenguaje a través de la historia, Gedisa, Barcelona, 1996.

3. Farge, Arlette, La vida frágil. Violencia, poderes y solidaridades en el París del siglo XVIII, Instituto Mora, México, 1994. Perry, Mary Elizabeth, Gender and Disorder in Early Modern Seville, Princeton University Press, New Jersey, 1990. Garrioch, David, Neighbourhood \& Community in Paris, 1740-1790, Cambridge University Press, Cambridge, 1986. Gowing, Laura, Domestic Dangers. Women, Words, and Sex in Early Modern London, Oxford University Press, Oxford, 1996.

4. Johnson, Lyman \& Lipsett-Rivera, Sonya (eds.), The Faces of Honor. Sex, Shame and Violence in Colonial Latin America, University of New Mexico Press, Albuquerque 1998. Undurraga Schüler, Verónica, "Honores transversales, honores polisémicos en la sociedad chilena del siglo XVIII" en Araya, Alejandra \& Candina, Azun \& Cussen, Celia (coord.), Del Nuevo al Viejo Mundo: Mentalidades y representaciones desde América, Fondo de Publicaciones Americanistas y Facultad de Humanidades de la Universidad de Chile, Santiago de Chile, 2008. Undurraga Schüler, Verónica, Los rostros del honor, Dibam Ediciones, Santiago de Chile, 2012. Fernández, María Alejandra, Honor e insultos. Buenos Aires, 1750-1820, Tesis de doctorado en Historia, Universidad de Buenos Aires, Buenos Aires, Argentina, 2014. Twinam, Ann, Vidas públicas, secretos privados. Género, honor, sexualidad e ilegitimidad en la Hispanoamérica colonial, FCE, Buenos Aires, 2009.

5. Esta línea está estrechamente asociada a los trabajos de Lipsett-Rivera, Sonya, "De Obra y Palabra: Patterns of insults in Mexico, 1750-1856", The Americas, Cambridge, vol. 54, n²4, 1998. Actualización posterior de la autora, "Los insultos en la Nueva España en el siglo XVIII" en Gonzalbo Aizpuru, Pilar (dir.), Historia de la vida cotidiana en México, tomo III El siglo XVIII, entre tradición y cambio, El Colegio de México- FCE, México, 2005. Lipsett-Rivera, Sonya, “Honor, familia y violencia en México" en Gonzalbo Aizpuru, Pilar \& Zárate Toscano, Verónica (coord.), Gozos y sufrimientos en la Historia de México, El Colegio de México - Instituto Mora, México, 2007.

6. Farge, Arlette, Efusión y tormento. El relato de los cuerpos. Historia del pueblo en el siglo XVIII, Katz Editores, Madrid, 2008, p. 71.

7. Ver especialmente los trabajos de Albornoz Vásquez, María Eugenia, "Sufrimientos individuales declinados en plural. La necesaria singularidad de los pelitos por injurias en Hispanoamérica colonial", Dossier coordinado por Langue, Frédérique \& Vidal, Edgar, "Histoire culturelle et histoire urbaine: hommage à Sandra Jatahy Pesavento", Nuevo Mundo Mundos Nuevos, $\mathrm{n}^{\circ} 10,2010$, http://nuevomundo.revues.org/60138, consultado el 10 de abril de 2012; "Umbrales sensibles de la modernidad temprana: los usos de la vergüenza en Chile, siglos XVIII y XIX", Nuevo Mundo Mundos Nuevos, n9, 2009, http://nuevomundo.revues.org/5565,consultado el 14 de diciembre de 2011; "La injuria de Palabra en Santiago de Chile, 1672-1822", Nuevo Mundo Mundos Nuevos, $\mathrm{n}^{\circ} 4$, 2004, http://nuevomundo.revues.org/240, consultado el 15 de abril de 2006.

8. Palacio, Juan Manuel \& Candioti, Magdalena (comp.), Justicia, política y derechos en América Latina, Prometeo, Buenos Aires, 2007, Introducción, p. 17.

9. Palacio, J. M. \& Candioti, M. (comp.), Justicia, política y derechos, Op. Cit., Introducción, p. 17.

10. Stern, Steve, Los pueblos indígenas del Perú y el desafío de la conquista española, Alianza, Madrid, 1986. Para perspectivas historiográficas que conciben a la justicia como un espacio de contrahegemonía, ver: Serulnikov, Sergio, “ 'Su verdad y su justicia'. Tomás Catari y la insurrección aymara de Chayanta, 1777-1780” en Walker, Charles (comp.), Entre la retórica y la insurgencia: las ideas y los movimientos sociales en los Andes, Siglo XVIII, Centro de Estudios regionales Andinos 'Bartolomé de Las Casas', Cusco, 1996. Serulnikov, Sergio, Conflictos sociales e insurrección en el mundo colonial andino. El norte de Potosí en el siglo XVIII, FCE, Buenos Aires, 2006.

11. Mallo, Silvia, La sociedad rioplatense ante la justicia. La transición del siglo XVIII al XIX, Publicaciones del AHPBA, Buenos Aires, 2004. Cicerchia, Ricardo, "De mujeres, varones y jueces. Familia popular y justicia en la ciudad de Buenos Aires (1777-1850)" en Perrin, Michel \& Perruchon, Marie (comp.), Complementariedad entre hombre y mujer. Relaciones de género desde la perspectiva amerindia, ABYA-YALA, Quito, 1997. Fradkin, Raúl (comp.), El poder y la vara. Estudios 
sobre la justicia y la construcción del Estado en el Buenos Aires rural, Prometeo, Buenos Aires, 2007. Fradkin, Raúl (comp.), 'La ley es tela de araña'. Ley, justicia y sociedad rural en Buenos Aires, 1780-1830, Prometeo, Buenos Aires, 2009. Vassallo, Jaqueline, Mujeres delincuentes. Una mirada de género en la Córdoba del siglo XVIII, Universidad Nacional de Córdoba, Córdoba, 2006. Rebagliati, Lucas, "Los pobres ante la justicia: discursos, prácticas y estrategias de subsistencia en Buenos Aires (1785-1821)", Boletín del Instituto de Historia Argentina y Americana Dr. Emilio Ravignani, Buenos Aires, $n^{\circ} 38$, 2013. Quinteros, Guillermo, La política del matrimonio. Novios, amantes y familias ante la justicia, Buenos Aires, 1776-1860, Prohistoria, Rosario, 2015. Ghirardi, Mónica, "Familia y maltrato doméstico. Audiencia episcopal de Córdoba, Argentina. 1700-1850", Revista Historia Unisinos, vol. 12, $\mathrm{n}^{\circ} 1$, Río de Janeiro, 2008.

12. Agüero, Alejandro, Castigar y perdonar cuando conviene a la República. La justicia penal de Córdoba del Tucumán, siglos XVII y XVIII, Centro de Estudios políticos y constitucionales, Madrid, 2008. Agüero, Alejandro, "Las categorías básicas de la cultura jurisdiccional" en Lorente Sariñena, Marta (coord.), De justicia de jueces a Justicia de leyes: Hacia la España de 1870, Consejo General del Poder Judicial, Madrid, 2007. Barriera, Darío (coord.), La justicia y las formas de la autoridad, ISHIR CONICET - Red Columnaria, Rosario, 2010. Barriera, Darío, "Lenguajes y saberes judiciales de los legos en el Río de la Plata (siglos XVI-XIX)” en Sozzo, Máximo (coord.), Historias de la cuestión criminal en la Argentina, Ed. Del Puerto, Buenos Aires, 2009. Barriera, Darío, "La ciudad y las varas: justicia, justicias y jurisdicciones (ss. XVI-XVII)”, Revista de Historia del Derecho, n³1, Instituto de Investigaciones de Historia del Derecho, Buenos Aires, 2003. Garriga, Carlos, "Sobre el gobierno de la justicia en Indias (siglos XVI-XVII)", Revista de Historia del Derecho, n³4, Buenos Aires, 2006. Garriga, Carlos, “Orden jurídico y poder político en el Antiguo Régimen”, ISTOR: Revista de Historia Internacional, México, año IV, n¹6, 2004. Hespanha, Antonio, La gracia del derecho. Economía de la cultura en la Edad Moderna, Centro de Estudios Constitucionales, Madrid, 1993. Cañeque, Alejandro, "Cultura vicerregia y Estado Colonial. Una aproximación crítica al estudio de la historia política de la Nueva España", Historia Mexicana, México, vol. LI, n¹, 2001. Owensby, Brian, "Pacto entre Rey lejano y súbditos indígenas: justicia, legalidad y política en Nueva España, siglo XVII”, Historia Mexicana, México, volumen LXI, n¹, 2011.

13. Fradkin, Raúl \& Robles, Nidia, "Juicios de desalojo y formas de resistencia subalterna en la campaña bonaerense durante la década de 1820", Ponencia presentada en las XVIII Jornadas de Historia económica, Mendoza, 18 al 20 de septiembre de 2002. Agradezco esta referencia, para el espacio urbano, a Cristian Poczynok.

14. Fernández, M. A., Honor e insultos, Op. Cit. En dicho período, que se inicia con posterioridad a la creación del virreinato, se concentran la mayor parte de las causas incoadas en la ciudad y concluye con la abolición de los cabildos en 1821, en el marco de la transformación institucional que siguió al afianzamiento del proceso independentista.

15. Johnson, Lyman \& Socolow, Susan, "Población y espacio en el Buenos Aires del siglo XVIII", Desarrollo Económico, Buenos Aires, vol. 20, nำ9, 1980. En su último trabajo, Johnson actualiza estas cifras, en base a nuevas estimaciones a partir de los registros bautismales. El cambio es muy significativo: para 1744 habría 14.500 habitantes, para 1778, 37.400 y para 1810, 76.450. Hemos utilizado los datos censales anteriores, que son los que hasta ahora se han tomado en cuenta en toda la bibliografía. Johnson, Lyman, Workshop of Revolution. Plebeian Buenos Aires and the Atlantic World, 1776-1810, Duke University Press, Durham and London, 2011, p. 29-30.

16. Halperin Donghi, Tulio, Reforma y disolución de los imperios ibéricos, Alianza, Madrid, 1985.

17. La caracterización del perfil social de los barrios está tomada de Di Meglio, Gabriel, ¡Viva el bajo pueblo! La plebe urbana de Buenos Aires y la política entre la Revolución de Mayo y el Rosismo, Prometeo, Buenos Aires, 2007, p. 47.

18. Esta caracterización de la plebe está tomada de Di Meglio, G., ¡Viva el bajo pueblo!, Op. Cit., p. 16-17. 
19. Pérez, Mariana, En busca de mejor fortuna. Los inmigrantes españoles en Buenos Aires desde el Virreinato a la Revolución de Mayo, Prometeo, Buenos Aires, 2010.

20. Archivo General de la Nación (AGN), Tribunales Criminales 1756-1827, Legajo (L) C $\mathrm{n}^{\circ} 1$, Expediente (E) 9 (1805). La querella se presenta en el Juzgado de Artillería, ante el Comandante, porque el marido de la querellada se desempeñaba como soldado miliciano de dicho cuerpo.

21. Agradezco esta precisión a Sebastián Rodríguez.

22. AGN, Tribunales Criminales, L C n $1, \mathrm{E}$ 9, f. 1 .

23. En el expediente nunca aparece una mención concreta sobre la zona de residencia, pero rastreando los datos de la pulpería que se menciona en el pleito, se pudo establecer el barrio. Agradezco esta referencia a Mariana Pérez, quien me aportó esta precisión a partir de su base de datos de los pulperos peninsulares.

24. Farge, A., La vida frágil, Op. Cit., p. 24.

25. AGN, Tribunales Criminales, $\mathrm{L} C \mathrm{n}^{\circ} 1, \mathrm{E} 9, \mathrm{f} .1 \mathrm{r}$.

26. AGN, Tribunales Criminales, L C nº $1, \mathrm{E} 9, \mathrm{f}$. 1r. Todo lo que figura subrayado está registrado de ese modo en el expediente original.

27. Ante el Coronel del Regimiento de Milicias de Infantería, porque Miguel Migolla era soldado de dicho cuerpo.

28. AGN, Tribunales Criminales, $\mathrm{L} C \mathrm{n}^{\circ} 1, \mathrm{E} 9, \mathrm{f} .5 \mathrm{r}$.

29. AGN, Tribunales Criminales, $\mathrm{L} C \mathrm{n}^{\circ} 1$, E 9, f. 6.

30. Ver las notas 5,6 y 8.

31. Lo hemos desarrollado con más detenimiento en Fernández, María Alejandra, "Defender, negociar y disputar la identidad: las representaciones femeninas en la arena judicial (Buenos Aires, fines del siglo XVIII - principios del s. XIX)", Ponencia presentada en las XIII Jornadas nacionales de Historia de las mujeres y VIII Congreso Iberoamericano de Estudios de género, FFyL-UBA/FSOC-UBA/UNQ, 24, 25, 26 y 27 de Julio de 2017.

32. Fernández, María Alejandra, "Reputaciones masculinas y definiciones socioculturales de la hombría. Buenos Aires, 1750-1810", Temas Americanistas, n³7, 2016, disponible en http:// institucional.us.es/tamericanistas/index.php?page=numero-37.

33. Para un análisis específico sobre los distintos significados de esta imposición, ver Albornoz Vásquez, María Eugenia, "El mandato de silencio perpetuo. Existencia, escritura y olvido de conflictos cotidianos. Chile, 1720-1840" en Cornejo, Tomás \& González, Carolina (dir.), Justicia, poder y sociedad: recorridos históricos. Chile, s. XVIII-XXI, Ed. Universidad Diego Portales, Santiago de Chile, 2007.

34. AGN, Tribunales Criminales, L C n ${ }^{\circ}$ 1, E 9, f. 16.

35. AGN, Tribunales Criminales, L C n 1 , E 9, f. 16.

36. Agüero, A., Castigar y perdonar, Op. Cit., p 29.

37. Archivo General de la Nación (AGN), Tribunales Criminales 1752-1825, Legajo (L) M n¹ (1819). El apellido aparece registrado de diferentes maneras; por cuestiones de claridad en la redacción mantendremos la primera. Ninguno de los involucrados sabía firmar, cada uno de los escritos fue firmado a ruego de la parte por diferentes individuos.

38. AGN, Tribunales Criminales, $\mathrm{L} \mathrm{M} \mathrm{n}{ }^{\circ} 1, \mathrm{f} 1 \mathrm{r}$. Todo el subrayado figura de ese modo en el original del expediente.

39. AGN, Tribunales Criminales, $\mathrm{L} M \mathrm{M}^{\circ} 1, \mathrm{f} 1 \mathrm{r}$.

40. AGN, Tribunales Criminales, $\mathrm{L} M \mathrm{n}^{\circ} 1, \mathrm{f} 1 \mathrm{r}$.

41. En nuestra área de estudio son más variadas las referencias a la animalización de las mujeres, mientras que en el caso de Chile, la principal figura invocada es la de "perra". Albornoz Vásquez, M. E. "La injuria de Palabra", Op. Cit.

42. Araya Espinosa, Alejandra, "La pureza y la carne: el cuerpo de las mujeres en el imaginario político de la sociedad colonial", Revista de Historia social y de las Mentalidades, Santiago de Chile, Año VIII, vol. 1/ 2, 2004, p. 74. 
43. Para una aproximación al orden de los cuerpos disciplinados y a las disonancias insoportables, ver Albornoz Vásquez, María Eugenia \& Argouse, Aude, "Mencionar y tratar el cuerpo: indígenas, mujeres y categorías jurídicas. Violencias del orden hispano colonial, Virreinato del Perú, s. XVII-XVIII", Nuevo Mundo Mundos Nuevos, n9, 2009, http:// nuevomundo.revues.org/53163, consultado el 28 de mayo de 2011. Para la violencia, Albornoz Vásquez, María Eugenia, "El precio de los cuerpos maltratados: discursos judiciales para comprar la memoria de las marcas de dolor. Chile, 1773-1813", Nuevo Mundo Mundos Nuevos, n9, 2009, http://nuevomundo.revues.org/55888, consultado el 19 de noviembre de 2011.

44. AGN, Tribunales Criminales, $\mathrm{L} \mathrm{M} \mathrm{n}{ }^{\circ} 1, \mathrm{f} 10$.

45. AGN, Tribunales Criminales, $\mathrm{L} M \mathrm{n}^{\circ} 1, \mathrm{f} 10$.

46. AGN, Tribunales Criminales, $\mathrm{L} \mathrm{M} \mathrm{n}^{\circ} 1, \mathrm{f} 19$.

47. AGN, Tribunales Criminales, $\mathrm{L} \mathrm{M} \mathrm{n}^{\circ} 1, \mathrm{f} 19$.

48. Por más que Dolores se asigne a sí misma y a su esposo el tratamiento de Don/Doña, Morella se los niega explícitamente.

49. Para los usos de la vergüenza, ver Albornoz Vázquez, M. E., "Umbrales sensibles”, Op. Cit.

50. Tomado de Zamora, Romina, Casa poblada y buen gobierno: oeconomia católica y servicio personal en San Miguel de Tucumán, siglo XVIII, Prometeo, Buenos Aires, 2017, p. 122-124.

51. AGN, Tribunales Criminales, $\mathrm{L} M \mathrm{n}^{\circ} 1, \mathrm{f} 18 \mathrm{r}$.

52. Farge, A., Efusión y tormento, Op. Cit., p. 59.

53. Albornoz Vásquez, M. E., "El mandato de silencio perpetuo", Op. Cit., la cita corresponde a la página 4 de la versión digital de la autora, en su perfil de Academia.edu.

54. Para análisis recientes sobre la figura del Alcalde de Barrio y sus transformaciones en el período posterior a la revolución de 1810, ver: Barriera, Darío, "Y en el principio, fue la justicia. Las alcaldías de barrio: visibilización de un desenredo en la cultura jurisdiccional (1770-1830), en Barriera, Darío (dir.), Justicias situadas. Instituciones, agentes, culturas y espacios (entre el Virreinato Rioplatense y la República Argentina), Ediciones de la UNLP, Buenos Aires, 2018. Zamora, Romina, "Jurisdicción económica, policía económica, economía política. La función de policía y las justicias menores en el Virreinato del Río de la Plata" en Barriera, D. (dir.), Justicias situadas, Op., Cit. Barriera, Darío, "El alcalde de barrio, de justicia a policía (Río de la Plata, 1770-1830)", Nuevo Mundo Mundos Nuevos, 2017, http://journals.openedition.org/nuevomundo/70602, consultado el 19 de octubre de 2017. Casagrande, Agustín, "Por una historia conceptual de la Seguridad. Los Alcaldes de Barrio de la Ciudad de Buenos Aires (1770-1820), Conceptos Históricos, Buenos Aires, $\mathrm{n}^{\circ} 1, \mathrm{p} .40-71$.

55. Creados en 1772 por el Gobernador Vértiz como Comisionados en dependencia de la Gobernación de Buenos Aires. Inicialmente las funciones preventivas estaban controladas por los Alcaldes de 1ro y 2do voto, pero después de 1812 pasaron a depender de la Intendencia de Policía. 56. Tomado de Barriera, D., "Y en el principio, fue la justicia", p. 142 y p. 150. El autor analiza el proceso de desjudicialización de esta figura y su progresiva transformación asociada al sentido moderno de la función policial.

57. Tomado de Barriera, D., "Y en el principio, fue la justicia", p. 149. Instrucción del Virrey Cisneros de 1809. Ver también Zamora, R., “Jurisdicción económica”, Op. Cit., p. 51 y p. 61.

58. Di Meglio, G., ¡Viva el bajo pueblo!, Op. Cit., p. 56-59.

59. Barriera, D., "Lenguajes y saberes", Op. Cit, p. 85. Ver también Brangier, Víctor \& Barriera, Darío, "Lenguajes comunes en 'Justicias de jueces'. Tratamientos historiográficos y fondos judiciales en Chile y Argentina”, Revista de Humanidades, Sevilla, n³2, 2015.

60. Barriera, D., "Lenguajes y saberes", Op. Cit, p. 85. 


\section{RESÚMENES}

Este artículo pone el foco en la relación entre injurias, justicias y desalojos en la ciudad de Buenos Aires, entre fines del siglo XVIII y principios del XIX. El objetivo es indagar en tres aspectos: las dinámicas de conflictividad y sociabilidad barrial; las expresiones explícitas o más sutiles de solidaridad, de reconocimiento o de denigración; la distancia entre expectativas y resultados a la hora de acudir a los juzgados. Para ello se atiende al problema de las culturas jurídicas y judiciales de los involucrados, a los costos imprevistos de la judicialización de los conflictos y a la posibilidad de exclusión social -como resultado de las discordias y el escándalo-, materializada en el riesgo de expulsión del barrio.

This article focuses on the relationship between slander, justice, and evictions in Buenos Aires in the late eighteen and early nineteenth century. It aims to explore three issues: the dynamics of neighbourhood conflict and sociability, the explicit or subtle expressions of solidarity, recognition or denigration, and the gap between expectations and results when bringing a case to court. In doing so, the research focuses on the judicial and juridical cultures of the people involved in the case, in the unforeseen expenses of the judicialisation of conflicts, and in the possibility of social exclusion -as a result of disagreements and the scandal- materialised in the risk of being evicted from the neighbourhood.

Cet article se concentre sur la relation entre injures, justices et expulsion à Buenos Aires, au tournant du XIXe siècle. Il examine trois questions: les dynamiques des conflits et de la sociabilité de voisinage ; les expressions explicites ou subtiles de solidarité ; la reconnaissance ou le dénigrement, et le fossé entre des attentes et les résultats de l'action en justice. Ce faisant, la recherche est centrée sur les cultures judiciaire et juridique des personnes impliquées dans l'affaire, sur les coûts imprévisibles de la judiciarisation des conflits et sur la possibilité d'une exclusion sociale -comme résultant des désaccords et du scandale-matérialisé dans le risque de se voir expulsé du quartier.

\section{ÍNDICE}

Palabras claves: Buenos Aires, siglos XVIII y XIX, injurias, desalojos, culturas judiciales Keywords: slave fugitives, jurisdictional culture, ecclesiastical justice, Río de la Plata, 18th century

Mots-clés: esclave fugitif, culture juridictionnelle, justice ecclésiastique, Rio de la Plata, XVIIIe siècle

\section{AUTOR}

\section{MARÍA ALEJANDRA FERNÁNDEZ}

Doctora en Historia, Universidad de Buenos Aires. Investigadora-docente del área de Historia, Universidad Nacional de General Sarmiento. Profesora adjunta y Docente, Departamento de Historia, Facultad de Filosofía y Letras, Universidad de Buenos Aires. Buenos Aires, Argentina. malejfernandez[at]gmail.com.

Esta investigación se inserta en el Proyecto Código 30/1107 "Familia e infancia. Identidades, conflictos, relaciones jerárquicas y órdenes socio-políticos en Buenos Aires, fines del siglo XVIII - 
comienzos del siglo XX", Directora Carolina Zapiola y Co-directora María Alejandra Fernández, Universidad Nacional de General Sarmiento, Buenos Aires, Argentina. Agradezco la lectura atenta y los enriquecedores comentarios de Fernanda Molina y Miriam Moriconi, así como las valiosas sugerencias de Raúl Fradkin para pensar -desde otro ángulo- la figura de los Alcaldes de Barrio 